\title{
Predictors of subclinical cardiovascular affection in Egyptian patients with juvenile idiopathic arthritis subtypes
}

\author{
Samah M. Alian ${ }^{1 *}$ D, Hanan A. Esmail ${ }^{2}$, Marwa M. Gabr ${ }^{1}$ and Enass A. Elewa ${ }^{1}$
}

\begin{abstract}
Background: To assess the subclinical cardiovascular affection in juvenile idiopathic arthritis (JIA) Egyptian patient subtypes using Doppler ultrasonography (US) for carotid and femoral arteries and detecting their predictors

Results: Forty percent of the patients were polyarticular type, while $40 \%$ were systemic onset and 20\% were oligoarticular. There was a statistically significant difference between JIA and controls in all parameters of subclinical atherosclerosis by ultrasonography except right external carotid velocity and (right and left) femoral velocity. There was also a highly significant increase in intima-media thickness (IMT) in systemic onset type of JIA. There was a statistically positive correlation between increased internal carotid velocity (right and left) and high erythrocyte sedimentation rate (ESR), high-sensitivity C-reactive protein (hs-CRP), lipid profile, and disease activity. High disease activity and lipid profile were valid predictors of subclinical atherosclerotic cardiovascular affection in JIA.

Conclusion: Increased cardiovascular risks and subclinical atherosclerosis in patients with JIA especially systemic onset type may be due to higher prevalence of multiple risk factors in these patients. Doppler ultrasonography is a simple, non-invasive technique which can be used to detect subclinical atherosclerosis in JIA. Control of disease activity by treat to target strategy and proper diet control should be applied for every patient with JIA especially those with systemic onset type for future prevention of cardiovascular disease.
\end{abstract}

Keywords: Subclinical atherosclerosis, Juvenile idiopathic arthritis, Carotid Doppler ultrasound, Femoral Doppler ultrasound, Intimal medial thickness (IMT)

\section{Background}

Juvenile idiopathic arthritis (JIA) is the most common pediatric rheumatic disease and is associated with significant long-term morbidity and mortality [1]. JIA, an autoimmune disorder, is caused by a combination of environmental and genetic factors [2]. JIA classification is based on predominant clinical manifestation and laboratory features within the first 6 months of disease [3].

As JIA is a chronic inflammatory disease, it has long-term effects on many organ systems, including the cardiovascular system [4]. Atherosclerosis is a chronic disease of the arteries

\footnotetext{
* Correspondence: dr_r18@yahoo.com

${ }^{1}$ Rheumatology and Rehabilitation Department, Faculty of Medicine, Zagazig University, Zagazig, Egypt

Full list of author information is available at the end of the article
}

in the adult population; however, atherosclerotic changes have their beginning in childhood. The severity of atherosclerosis correlates with the number and intensity of risk factors such as high body mass index, blood pressure, total cholesterol, low-density lipoprotein (LDL), triglyceride concentration, and low high-density lipoprotein (HDL) [5]. The inflammation is considered to be an essential factor in atherosclerosis development by stimulating atheroma formation, destabilization of damaged atherosclerotic plaques, and formation of occlusive thrombi [6].

Inflammation is involved in all aspects of atherogenesis. From the initation of endothelial cell activation to foam cell formation to the development of an atherosclerotic lesion and to the rupture of the "vulnerable" fibrous cap, all these eventually result in acute coronary

\section{Springer Open}

(ㅇ The Author(s). 2020 Open Access This article is licensed under a Creative Commons Attribution 4.0 International License, which permits use, sharing, adaptation, distribution and reproduction in any medium or format, as long as you give appropriate credit to the original author(s) and the source, provide a link to the Creative Commons licence, and indicate if changes were made. The images or other third party material in this article are included in the article's Creative Commons licence, unless indicated otherwise in a credit line to the material. If material is not included in the article's Creative Commons licence and your intended use is not permitted by statutory regulation or exceeds the permitted use, you will need to obtain permission directly from the copyright holder. To view a copy of this licence, visit http://creativecommons.org/licenses/by/4.0/. 
syndrome and potentially death. An inflammatory lesion is the site of interaction among endothelial cells, monocytes, and T cells [7].

The association of JIA with increased incidence of subclinical atherosclerosis and a possible increased future cardiovascular risk has not been adequately investigated [8]. The ultrasonography is an advancing technology and a safe and non-invasive imaging which has led to significant improvements in diagnosis [9]. Doppler ultrasound (US) is the method that enables the analysis of total blood flow and measures the diameter of the arteries [10].

The aim of this study was to assess the subclinical cardiovascular affection in JIA Egyptian patient subtypes using Doppler ultrasonography for carotid and femoral arteries and detecting their predictors.

\section{Methods}

\section{Patients}

This study was carried out in outpatient and inpatient clinics in the Rheumatology and Rehabilitation Department and Radiodiagnosis Department, Faculty of Medicine, on 60 subjects who were divided into 2 groups.

\section{Group I (juvenile idiopathic arthritis group)}

It included 30 patients who fulfilled the International League of Associations for Rheumatology diagnostic criteria for juvenile idiopathic arthritis, according to the 2011 revised American College of Rheumatology guidelines [11].

\section{Group II (control group)}

Thirty normal volunteers were studied, and they were age and sex matched with the patients.

Written informed consent was obtained from parents, and verbal assent was obtained from all children and adolescents for their study participation. The study was approved by the local ethical committee of Zigazig University Hospitals (number 3052/20-9-2017).

\section{Exclusion criteria}

The exclusion criteria are as follows: onset of disease after 16 years old, hypertension, diabetes mellitus, renal insufficiency, obesity, evidence of cardiovascular disease or received drugs affecting the cardiovascular system (antihypertensive drugs, nitrate, and statins), smoking, family history of cardiovascular disease, and patients with inflamed synovium related to trauma, septic arthritis, malignancy, or other bone disease.

\section{Type of study}

This is a case control study.

\section{Data collection}

Full history taking was done (with special stress on morning stiffness in minutes; types and pattern of joints affected; past and family history of diabetes mellitus, hypertension, or cardiovascular affection; and history of medications used for disease control either steroid, conventional disease-modifying drugs, or biological disease-modifying drugs).

General and local musculoskeletal examination for each case was done with stress on body mass index, blood pressure, and cardiovascular examination, and also joint inspection for swelling, palpation for tenderness, and range of motion for the following joints: cervical spine, elbow, wrist, metacarpophalangeal, proximal interphalangeal, interphalangeal of the thumb, hip, knee, and ankle.

\section{Laboratory investigations}

Complete blood picture; erythrocyte sedimentation rate (ESR); high-sensitivity C-reactive protein (hs-CRP); liver function test; kidney function tests; lipid profile assessment including total cholesterol, HDL, and LDL; and serum triglycerides were performed using Dimension RxL max auto-analyzer (Siemens Healthcare Diagnostics Ltd., UK). Fasting blood sugar, glycoslated hemoglobin, and rheumatoid factor were also investigated.

\section{Assessment of disease activity}

We used the Juvenile Arthritis Disease Activity Score (JADAS-27) [12] that included the following four measures: physical global assessment of disease activity, parent/patient global assessment of well-being, count of joint with active disease, and ESR. The JADAS-27 was calculated as the simple linear sum of the score of its 4 components; the disease activity according to JADAS-27 was considered inactive $(<1)$, low (1.1-2 and $1.1-3.8)$, moderate (2.1-4.2 and 3.9-8.5), and high (> 4.2 and $>8.5$ ), respectively [13].

\section{Ultrasonography}

Carotid Doppler ultrasonography (US) is a popular tool for evaluating atherosclerosis of the carotid artery. All high-resolution B-mode ultrasonography of the right and left carotid arteries was performed with a linear 7.5$\mathrm{mHz}$ transducer (Philips) by a single reader unaware of the patients' status. The subjects were placed in the supine position with the head turned slightly to the left and right. The optimal patient head position is tilted about $45^{\circ}$ away from the artery being examined. The common, internal, and external carotid arteries were identified by combined B-mode and color Doppler US examination. A careful search was performed to obtain an optimal visualization of the vessel wall demonstrating the typical double line representing the intima-media layer. Carotid IMT was defined as the distance between 
the leading edge interface of the far wall and the leading edge interface of the median adventitia interface of the far wall with an automated edge tracking method. The ultrasonic protocol requires the visualization of the near and the far wall of the right and left common carotid, internal carotid artery, and bifurcation in three different projections: anterior, lateral, and posterior, for a total of 18 carotid segments per patient; these determinations were averaged carotid IMT: normal CIMT value $\leq 0.5$ $\mathrm{mm}$ [14]. Normal blood flow velocity $<125 \mathrm{~cm} / \mathrm{s}$ [15].

In femoral imaging, the patient lays in supine position with the hip slightly externally rotated and the knee flexed. The common femoral artery was scanned $2 \mathrm{~cm}$ proximal to its bifurcation, and superficial femoral artery $2 \mathrm{~cm}$ distal to common femoral artery bifurcation on both sides. In femoral IMT, normal $\leq 0.5 \mathrm{~mm}$ [16]. Normal blood flow velocity $<125 \mathrm{~cm} / \mathrm{s}$ [17].

\section{Statistical methods}

All data were collected, tabulated, and statistically analyzed using SPSS 20.0 for Windows (SPSS Inc., Chicago, IL, USA). Quantitative data were expressed as the mean $\pm \mathrm{SD}$, and qualitative data were expressed as absolute frequencies (number) and relative frequencies (percentage). Student's $t$ test was used to compare between two groups of normally distributed variables. $F$ (ANOVA test) was used between more than two dependent groups of normally distributed variables. Percentage of categorical variables were compared using chi-square test or Fisher's exact test when appropriate. Pearson's correlation coefficient was calculated to assess the relationship between various study variables, the plus $(+)$ sign indicates direct correlation and the minus (-) sign indicates inverse correlation; also, values near to 1 indicate strong correlation and values near 0 indicate weak correlation. Multiple regression was used for detecting predicting factors for a dependant variable on several independent variables. All tests were two-sided. A $p$ value $\leq 0.05$ was considered statistically significant (S), and $>0.05$ was considered statistically insignificant (NS).

\section{Results}

This study included 60 subjects: 30 of them were suffering from JIA, and the other 30 subjects (control group) were normal volunteers apparently free from any disease who were age and sex matched with the JIA group. There was no statistically significant difference between the patients and controls as regards age, sex, and body mass index (Table 1).

As regards JIA patient subtypes, $40 \%$ were systemic type, $40 \%$ polyarthritis type, and $20 \%$ oligoarticular type of JIA patients.

When comparing parameters of subclinical atherosclerosis by ultrasound, there was a statistically significant difference between JIA patients and healthy controls as regards all parameters of subclinical atherosclerosis by ultrasound except the right external carotid velocity and (right and left) femoral velocity (Table 2).

Our results found a statistically significant difference between the subtypes of juvenile idiopathic arthritis patients as regards IMT of examined arteries and velocity except the left femoral velocity $(p<0.05)$. There was a highly significant increase in IMT of the common carotid arteries and internal carotid blood flow velocity in both the right and left sides in systemic type more than polyarthritis and oligoarthritis types (Table 3 ).

When we studied the correlation between the subclinical atherosclerosis parameters by US and patients' characterstics, we found a significant correlation between the right and left internal carotid artery velocity and the right and left common carotid artery IMT with demographic characters, parameters of disease activity, and laboratory parameters of JIA patients $p \leq 0.05$ except for fasting blood sugar. Significant negative correlation between HDL and the right internal carotid artery velocity is shown in Fig. 1, and significant positive correlation between the JADAS-27 and right common carotid artery IMT is shown in Fig. 2.

It was observed that low HDL level and high ESR are significant predictors for increased right internal carotid velocity among JIA patients $(p \leq 0.05)$ and shows that increased LDL level and active joints are significant predictors for increased left internal carotid velocity among JIA patients $(p \leq 0.05)$. From our results, we found also that morning stiffness, low HDL, and high LDL are significant predictors for increased right common carotid IMT among JIA patients $(p \leq 0.05)$ and show that increased morning stiffness and high LDL are significant

Table 1 Demographic data of the studied groups

\begin{tabular}{|c|c|c|c|c|}
\hline Variables & Juvenile idiopathic arthritis $(n=30)$ & Control $(n=30)$ & Test of sig & $p$ \\
\hline Age, mean \pm SD & $16.4 \pm 10$ & $17.3 \pm 9.8$ & $t=0.4$ & 0.7 (NS) \\
\hline \multicolumn{5}{|l|}{ Sex } \\
\hline Female (\%) & $19(63)$ & $20(67)$ & $x^{2}=0.07$ & 0.7 (NS) \\
\hline Male (\%) & $11(37)$ & $10(33)$ & & \\
\hline Body mass index, mean \pm SD & $20.3 \pm 6.2$ & $22 \pm 5$ & $t=1.2$ & 0.2 (NS) \\
\hline
\end{tabular}

$X^{2}=$ chi square test, $t=$ Student's $t$ test of significance. $S D$ standard deviation, NS insignificant 
Table 2 Comparison between juvenile idiopathic arthritis patients and healthy controls as regards parameters of subclinical atherosclerosis by ultrasonography

\begin{tabular}{|c|c|c|c|c|}
\hline & Juvenile idiopathic arthritis patients $(N=30)$ & Control $(N=30)$ & $t$ & $p$ \\
\hline Right internal carotid velocity & $112.7 \pm 49$ & $80.9 \pm 16$ & 3.3 & $0.002^{*}$ \\
\hline Right external carotid velocity & $77.5 \pm 14$ & $74.5 \pm 15$ & .8 & 0.4 \\
\hline Right common carotid velocity & $108 \pm 44.5$ & $83.4 \pm 16$ & 2.8 & $0.007^{*}$ \\
\hline Right common carotid intima thickness & $0.65 \pm 0.11$ & $0.48 \pm 0.02$ & 7.8 & $0.00001^{*}$ \\
\hline Left internal carotid velocity & $119 \pm 31$ & $77.6 \pm 22.3$ & 5.9 & $0.0001^{*}$ \\
\hline Left external carotid velocity & 90. \pm 20 & $74.3 \pm 12.2$ & 3.7 & $0.0001^{*}$ \\
\hline Left common carotid velocity & $115.6 \pm 52$ & $80.9 \pm 14$ & 3.5 & $0.001^{*}$ \\
\hline Left common carotid intima thickness & $0.64 \pm 0.1$ & $0.47 \pm 0.04$ & 7.9 & $0.00001^{*}$ \\
\hline Right femoral velocity & $73 \pm 23$ & $67.3 \pm 9.87$ & 1.2 & 0.2 \\
\hline Right femoral intima thickness & $0.53 \pm 0.04$ & $0.48 \pm 0.03$ & 4.9 & $0.0001^{*}$ \\
\hline Left femoral velocity & $71.9 \pm 19$ & $72.9 \pm 10.5$ & 0.2 & 0.8 \\
\hline Left femoral intima thickness & $0.53 \pm 0.04$ & $0.48 \pm 0.03$ & 4.3 & $0.0001^{*}$ \\
\hline
\end{tabular}

*Statistically significant $p<0.05$

predictors for increased left common carotid IMT among JIA patients $(p \leq 0.05)$ (Table 4$)$.

\section{Discussion}

Chronic inflammation has been recognized as a risk factor in the pathogenesis of atherosclerosis. Thus, the interplay between traditional risk factors, exposure to corticosteroids, and chronic inflammation can probably create a perfect storm for early atherogenesis in the JIA population leading to increased incidence of cardiovascular diseases in the long term [18]. Subclinical atherosclerosis can be assessed in research work using some non-invasive procedures for the evaluation of structural changes in the arterial wall as blood flow velocity and carotid IMT by Doppler US [19].

We assessed the subclinical atherosclerosis in (JIA) patient subtypes and their relation to potential risk factors using carotid and femoral doppler ultrasonography, and we found in our results the following: 30 JIA patients and 30 controls were included, and there was no significant difference in age, sex, and body mass index between the patients and controls. Also, we found in our study that $40 \%$ of our cases were systemic type, $40 \%$ polyarthritis type, and $20 \%$ oligoarthritis type.

In contrast to our finding, Ahmad et al. [20] found $42 \%$ had oligoarticular type, $34 \%$ had polyarticular type,

Table 3 Comparison between juvenile idiopathic arthritis patients subtypes as regard parameters of subclinical atherosclerosis by ultrasonography

\begin{tabular}{|c|c|c|c|c|c|}
\hline & \multicolumn{3}{|l|}{ Juvenile idiopathic arthritis } & \multirow[t]{2}{*}{$f$} & \multirow[t]{2}{*}{$p$} \\
\hline & Oligarthritis $(n=6)$, mean \pm SD & Polyarthrits $(n=12)$, mean \pm SD & Systemic $(n=12)$, mean \pm SD & & \\
\hline Right internal carotid velocity & $76.3 \pm 16.4$ & $72.8 \pm 11.6$ & $170.8 \pm 7.4^{*}$ & 265 & $0.0001(\mathrm{~S})$ \\
\hline Right external carotid velocity & $66.7 \pm 11.5$ & $64.7 \pm 7.5$ & $88.3 \pm 7.3^{*}$ & 27 & $0.0001(S)$ \\
\hline Right common carotid velocity & $81 \pm 1.5$ & $73 \pm 15$ & $157 \pm 25^{*}$ & 67 & $0.0001(S)$ \\
\hline $\begin{array}{l}\text { Right common carotid intima } \\
\text { thickness }\end{array}$ & $0.49 \pm 0.01$ & $0.61 \pm 0.05$ & $0.78 \pm 0.04^{*}$ & 118 & $0.0001(S)$ \\
\hline Left internal carotid velocity & $81.7 \pm 23.8$ & $111 \pm 11.8$ & $145 \pm 24^{*}$ & 22 & $0.0001(S)$ \\
\hline Left external carotid velocity & $80.7 \pm 19$ & $85 \pm 12$ & $101 \pm 23^{*}$ & 3.4 & $0.048(S)$ \\
\hline Left common carotid velocity & $75.7 \pm 14.5$ & $73.8 \pm 11.5$ & $177.5 \pm 5.3^{*}$ & 365 & $0.0001(S)$ \\
\hline $\begin{array}{l}\text { Left common carotid intima } \\
\text { thickness }\end{array}$ & $0.49 \pm 0.01$ & $0.59 \pm 0.02$ & $0.75 \pm 0.05^{*}$ & 152 & $0.0001(S)$ \\
\hline Right femoral velocity & $44 \pm 15.4$ & $81.7 \pm 18^{*}$ & $78.58 \pm 20$ & 9 & $0.001(S)$ \\
\hline Right femoral intima thickness & $0.5 \pm 0$ & $0.5 \pm 0$ & $0.57 \pm 0.04^{*}$ & 16 & $0.0001(S)$ \\
\hline Left femoral velocity & $59.3 \pm 11$ & $71.6 \pm 15$ & $78.6 \pm 24$ & 2 & 0.13 (NS) \\
\hline Left femoral intima thickness & $0.5 \pm 0$ & $0.5 \pm 0$ & $0.57 \pm 0.05^{*}$ & 16 & $0.0001(\mathrm{~S})$ \\
\hline
\end{tabular}

$f=$ ANOVA test; $S$ significant, $N S$ non-significant

*LSD was for the systemic onset subtype in all subclinical atherosclerosis parameters except right femoral velocity was for the polyarticular subtype 


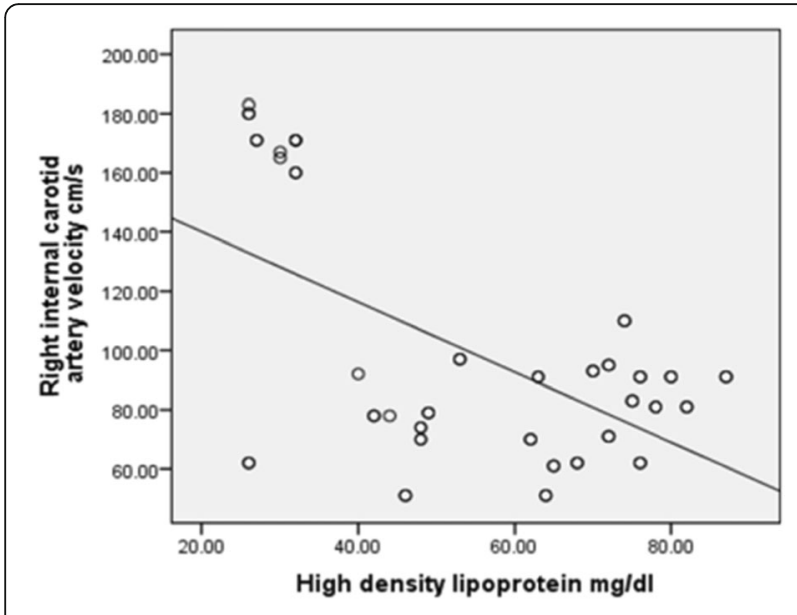

Fig. 1 Negative correlation between high-density lipoprotein (milligrams/deciliter) and right internal carotid artery velocity (centimeters/second)

and $24 \%$ had systemic type of JIA. Ebraheem et al. [21] reported oligoarticular, polyarticular, and systemic types of JIA were $45.45 \%, 27.27 \%$, and $27.27 \%$, respectively. Also, the prevalence of oligoarticular category was $51.1 \%$ in Nordal et al. [22] and was $65.2 \%$ in Picarelli et al. [23] study which were higher than that in our study, and this contrast may be explained by that most of the systemic subtype patients who needed biological therapy were referred to our hospital even from insurance hospitals for a specialized healthcare service

We reported a statistically significant decrease in HDL with significant increase in ESR, hs-CRP, total cholesterol, LDL, and triglyceride level in patients than in

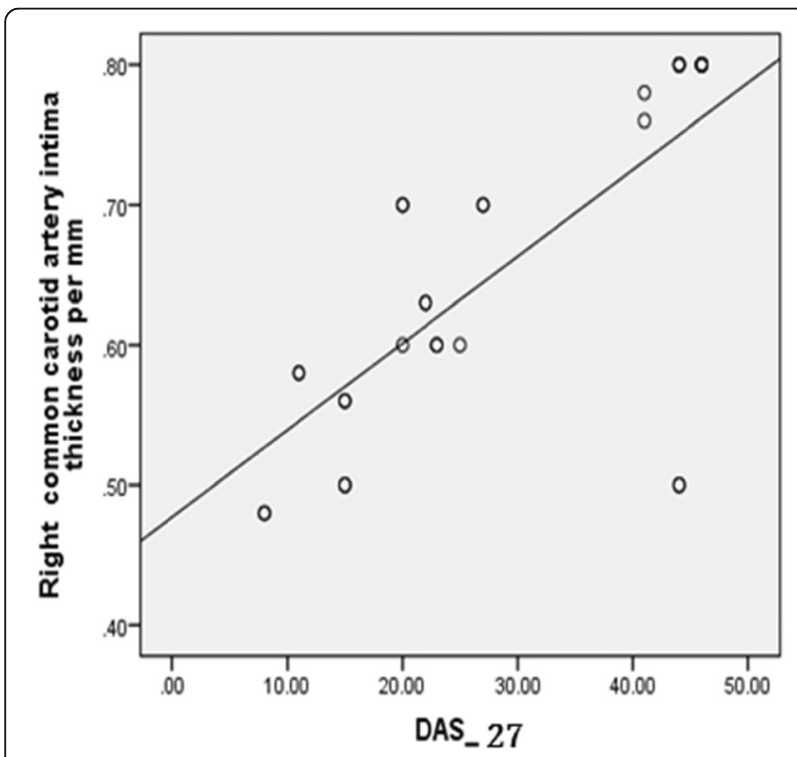

Fig. 2 Positive correlation between right common carotid artery intima-media hickness and JADAS-27 controls. In agreement with us, Urban et al. [24] revealed increased concentrations of total cholesterol, LDL, and triglycerides with decreased concentrations of HDL in early JIA patients and absence of clinical signs of obesity. Gonçalves et al. [25] found reduced levels of HDL in 51 children with JIA compared with healthy controls, with lower levels of LDL and triglycerides. Marangoni et al. [26] found decreased levels of HDL in patients with polyarticular JIA. Breda et al. [27] found JIA children have increased levels of inflammatory markers, proinflammatory cytokines, total cholesterol, triglycerides, and LDL cholesterol.

Also, Aulie [28] studied 87 patients with wellcharacterized JIA and 87 randomly selected age- and gender-matched controls and reported levels of hs-CRP to be higher in patients than in controls. In contrast to our results, Jednacz and Rutkowska-Sak [29] found no differences between two groups as regards lipid profile and hs-CRP. Also, Pickard [30] reported that there was no significant difference in LDL, cholesterol, or CRP in JIA patients in comparison with controls. It could be explained by a relatively low number of patients.

As regards Doppler US findings, we found a higher IMT of the right and left carotid arteries among JIA patients than healthy controls with statistically significant difference.

In agreement with us, Ebraheem et al. [21] and Breda et al. [27] reported that carotid IMT was significantly higher among JIA patients as compared to controls with no significant difference among JIA subtypes. Compatible also with our results, there was increased IMT in JIA patient in comparison with controls in the study by Głowińska-Olszewska et al. [31]. Similarly, the mean IMT value was higher in the patients with JIA than in the control subjects according to Ilisson et al. [1]. And in accordance with our results also, US examination of the participants in Ahmad et al. [20] study revealed the carotid IMT of the JIA patients was higher compared with controls.

In contrast to our results, Satija et al. [32], Vlahos et al. [8], Evenesen et al. [33], and Pickard [30] did not demonstrate differences in IMT between healthy children and children with JIA. This discrepancy probably reflects differences in study population regarding JIA subtypes involved, disease duration, and current medications. Jednacz and Rutkowska-Sak [29] did not demonstrate differences in IMT between healthy children and children with JIA, but this study did not include children with systemic type in which the intensity of the inflammatory process was particularly high.

We found a highly significant increase in both carotid and femoral IMT and blood flow velocity in systemic subtype of JIA patients except for the left femoral velocity. 
Table 4 Multiple regression analysis to predict risk factors for abnormal right and left internal carotid velocity and right and left common carotid intima-media thickness among juvenile idiopathic arthritis patients

\begin{tabular}{|c|c|c|c|c|c|}
\hline & \multirow{2}{*}{$\begin{array}{l}\text { Unstandardized } \\
\text { coefficients }\end{array}$} & \multirow[t]{2}{*}{$t$} & \multirow[t]{2}{*}{$p$} & \multicolumn{2}{|c|}{ 95\% confidence interval } \\
\hline & & & & Lower limit & Upper limit \\
\hline \multicolumn{6}{|c|}{ Variables for right internal carotid artery velocity } \\
\hline $\mathrm{HDL}$ & -1.84 & 2.3 & $0.006(S)$ & -3.94 & -0.2 \\
\hline ESR & 0.67 & 2.2 & $0.029(S)$ & 0.043 & 1.29 \\
\hline Constant & 143.7 & & & & \\
\hline \multicolumn{6}{|c|}{ Variables for left internal carotid artery velocity } \\
\hline Number of active joints & 1.56 & 2.6 & $0.016(S)$ & 0.3 & 2.8 \\
\hline LDL & 0.8 & 2.7 & $0.01(\mathrm{~S})$ & 0.2 & 1.4 \\
\hline Constant & 0.98 & & & & \\
\hline \multicolumn{6}{|c|}{ Variables for right common carotid artery (IMT) } \\
\hline Morning stiffness & 0.003 & 2.617 & .015 & 0.001 & 0.006 \\
\hline $\mathrm{HDL}$ & 0.01 & 2.786 & .010 & .003 & .017 \\
\hline LDL & 0.005 & 3.485 & .002 & 0.002 & .007 \\
\hline Constant & -0.674 & & & & \\
\hline \multicolumn{6}{|c|}{ Variables for left common carotid artery (IMT) } \\
\hline Morning stiffness & 0.003 & 2.129 & .043 & 0.000 & 0.005 \\
\hline LDL & 0.005 & 3.796 & .001 & 0.002 & 0.007 \\
\hline Constant & -0.31 & & & & \\
\hline
\end{tabular}

$H D L$ high-density lipoprotein, ESR erythrocyte sedimentation rate, $L D L$ low-density lipoprotein, $I M T$ intima-media thickness

In agreement with our results, Vlahos et al. [8] reported that there was a difference in IMT among children with oligoarticular, polyarticular, or systemic disease. IMT was significantly increased in patients with systemic compared to oligoarticular disease. IMT was also higher in systemic compared to polyarticular disease, although this did not reach statistical significance, suggesting a greater cardiovascular risk in this subgroup of patients. Increased IMT in patients with systemic compared to oligoarticular and polyarticular JIA observed in the present study was attributed to differences in age and other classic cardiovascular risk factors such as body mass index, lipids, and blood pressure, as well as disease-related features such as disease activity and corticosteroid treatment. Also, Ahmad et al. [20] concluded that JIA patients with subclinical atherosclerosis, with systemic disease, and with active disease are at greatest risk of developing subclinical heart failure [20].

In contrast, Breda et al. [27] found that IMT significantly differs between patients with oligo- and polyarthritis not systemic. Similarly, Pietrewicz and Urban [34] found higher IMT in the polyarthritis group compared with oligoarthritis children $(0.46 \mathrm{~mm}$ vs. $0.43 \mathrm{~mm})$. Also, Ebraheem et al. [21] and Evensen et al. [33] found no significant difference among JIA subtypes as regards carotid IMT, and this might have been explained by the fact that the study group did not include children with a systemic disease where the intensity of inflammatory lesions is especially high.

In our study, there was a significant negative correlation between common carotid arteries, internal carotid artery (right and left) IMT, and atherosclerosis parameters of JIA patients such as age, duration of disease, and HD lipoprotein, while we found a significant positive correlation with subclinical atherosclerosis parameters of JIA patients such as morning stiffness duration, global assessment, parent assessment, JADAS-27, number of active joint, ESR, cholesterol, triglyceride, LDL, hs-CRP, HbA1c. In agreement with our study, Breda et al. [27], Dessein et al. [35], and Acevedo et al. [36] revealed that carotid IMT significantly correlated with cholesterol and LDL levels.

In our study, the morning stiffness and LD and HD lipoproteins are significant predictors for the right common carotid IMT versus morning stiffness and LD lipoprotein for the left common carotid IMT. Also, the LD lipoprotein level and number of active joints were significant predictors for the left internal carotid velocity.

Evensen et al. [33] found that patients who had a JADAS score above the median value of 4.75 had higher IMT values than the patients with a score below the median value (mean \pm SD $0.56 \pm 0.08$ vs. $0.60 \pm 0.06, p=$ 0.03 ), but still not significantly different from the controls; this may suggest more subclinical atherosclerosis 
in patients with a more active JIA disease [33]. Polak et al. [37] reported that total cholesterol was not correlated to common carotid artery IMT and age was the strongest predictor of common carotid artery IMT. In addition, HDL cholesterol, smoking, hypertension, and diabetes had a significant relation to the IMTs of both common carotid arteries, but he did not differentiated between the right and left side [37]. Future follow-up studies to investigate the effect of medical treatment on the cardiovascular risks in children and adolescents with JIA are needed. The limitation of the study was that the BMI, nutritional profile, and family history of cardiovascular disease were not included in the study.

\section{Conclusion}

Finally, there is increased risk of cardiovascular disease in JIA patients although clinical signs are rare in children. It is unclear as to whether the risk extended to all subtypes or only to those with sustained inflammation, but it is more in systemic onset and persistent active polyarticular types due to their higher level of systemic inflammation. JIA is considered a cardiovascular risk as part of generic health advice within routine clinical care. Doppler US is a simple, non-invasive technique that could be used to detect subclinical atherosclerosis in JIA. Regular follow-up for early detection of atherosclerosis in JIA using Doppler US even if no symptoms are present was recommended. Further research is needed to define the mechanism of atherosclerosis in JIA patients. Control of disease activity by treat to target strategy and proper diet control should be applied for every patient with JIA especially those with systemic onset type for future prevention of cardiovascular disease.

\section{Abbreviations}

ESR: Erythrocyte sedimentation rate; HDL: High-density lipoprotein; hsCRP: High-sensitivity C-reactive protein; IMT: Intima-media thickness; JADAS 27: Juvenile Arthritis Disease Activity Score; JIA: Juvenile idiopathic arthritis; LDL: Low-density lipoprotein; US: Ultrasonography

\section{Acknowledgements}

No specific acknowledgements

\section{Authors' contributions}

SA had contributed to the conception and design of the work and the interpretation of data, had revised the work, had approved the submitted version (and any substantially modified version), and finally had agreed to be personally accountable for her own contributions and to ensure that questions related to the accuracy or integrity of any part of the work, even the ones in which she was not personally involved, are appropriately investigated, resolved, and the resolution documented in the literature. HE had performed the carotid and femoral Doppler study and made the interpretation of their results. MG had contributed to the conception and design of the work; the acquisition, analysis, and interpretation of data; the creation of new software used in the work; and the writing of the work. EE had contributed to the conception and design of the work, had revised the work, and also had approved the submitted version (and any substantially modified version). All authors have read and approved the final manuscript.

\section{Funding}

No funding for this article.
Availability of data and materials

Not applicable

\section{Ethics approval and consent to participate}

Written informed consent was obtained from parents, and verbal assent was obtained from all children and adolescents for their study participation. The study was approved by the local ethical committee of Zagazig University Hospitals (number 3052/20-9-2017).

\section{Consent for publication}

Written informed consent was obtained from parents, and verbal assent was obtained from all children and adolescents for the publication of the results of this research.

\section{Competing interests}

No conflict of interest.

\section{Author details}

${ }^{1}$ Rheumatology and Rehabilitation Department, Faculty of Medicine, Zagazig University, Zagazig, Egypt. ${ }^{2}$ Radiodiagnosis Department, Faculty of Medicine, Zagazig University, Zagazig, Egypt.

Received: 25 March 2020 Accepted: 5 May 2020

Published online: 09 June 2020

\section{References}

1. Ilisson J, Zagura M, Zilmer K et al (2015) Increased carotid artery intimamedia thickness and myeloperoxidase level in children with newly diagnosed juvenile idiopathic arthritis. Arthr Res Ther 17:180-187

2. Ravelli A, Martini A (2007) Juvenile idiopathic arthritis. Lancet 369:767-778

3. Kahn P (2009) Juvenile idiopathic arthritis: current and future therapies. Bull NYU Hosp Jt Dis 67:291-302

4. Kavey RE, Allada V, Daniels SR et al (2006) Cardiovascular risk reduction in high-risk pediatric patients: a scientific statement from the American Heart Association Expert Panel on Population and Prevention Science; the Councils on Cardiovascular Disease in the Young, Epidemiology and Prevention, Nutrition, Physical Activity and Metabolism, High Blood Pressure Research, Cardiovascular Nursing, and the Kidney in Heart Disease; and the Interdisciplinary Working Group on Quality of Care and Outcomes Research: endorsed by the American Academy of Pediatrics. Circulation 114:2710 2738

5. Cassidy J, Petty R, Laxer R et al (2011) Textbook of pediatric rheumatology, 5 th edn. Sauders Elsevier, Philadelphia, pp 206-208

6. Silva D, Pais de and Lacerda A (2012): High sensitivity C-reactive protein as a biomarker of risk in coronary artery disease. Rev Port Cardiol;31 (11):733-745.

7. Packard RR, Libby P (2008) Inflammation in atherosclerosis: from vascular biology to biomarker discovery and risk perdiction. Clin Chem 54(1):24-38

8. Vlahos AP, Theocharis P, Bechlioulis A et al (2011) Changes in vascular function and structure in juvenile idiopathic arthritis. Arthritis Care Res 63: 1736-1744

9. Tang GL, Chin J, Kibbe MR (2010) Advances in diagnostic imaging for peripheral arterial disease. Expert Rev Cardiovasc Ther 8:1447-1455

10. Renshaw A, Whitwell KA, Berger $L$ et al (2007) Butler PE. The use of color Doppler ultrasound in the assessment of vessels for facial transplantation. Ann Plast Surg 59:82-86

11. Petty RE, Southwood TR, Manners P et al (2004) International League of Associations for Rheumatology classification of juvenile idiopathic arthritis: second revision. Edmonton J Rheumatol 31:390-392

12. Consolaro A, Ruperto N, Bazso A et al (2009) Development and validation of composite disease activity score for juvenile idiopathic arthritis. Arthritis Rheum:658-666

13. Consolaro A, Giancane G, Schiappapietra B et al (2016) Clinical outcome measures in juvenile idiopathic arthritis. Peditar Rheumatol Online 14(1):23

14. Liviakis L, Pogue B, Parmothy P et al (2010) Carotid intima-media thickness for the practicing lipidologist. J Clin Lipidol 4:24-35

15. Grant EG, Benson CB, Moneta GL et al (2003) Carotid artery stenosis:gray scale and Doppler US diagnosis-Society of Radiodiagnosis in Ultrasound consensus conference. Radiology 229:340-346

16. Wang GJ, Layne AJ, Mohler ER et al (2012) PS170 A cross-sectional analysis of femoral artery intima-media thickness. J Vasc Surg 55:70S 
17. Gerhard-Herman M, Julius M, Gardin, et al., (2006): Guidelines for non invasive vascular laboratory testing: a report from the American Society of Echocardiography and the Society of Vascular Medicine and Biology. J Am Soc Echocardiogr 956-971.

18. Barsalou J, Bradley TJ, Silverman ED (2013) Cardiovascular risk in pediatriconset rheumatological diseases. Arthr Res Ther 15:212-224

19. Townsend RR, Wilkinson IB, Schiffrin EL et al (2015) Recommendations for improving and standardizing vascular research on arterial stiffness: a scientific statement from the American Heart Association. Hypertension 66:698-722

20. Ahmad HS, Othman G, Farrag SE et al (2016) Subclinical heart failure in juvenile idiopathic arthritis: a consequence of chronic inflammation and subclinical atherosclerosis. Egypt Rheumatol Rehabil 43:78-83

21. Ebraheem MF, Sallam RA-ER, Mohsen MA et al (2018) Vascular cell adhesion molecule-1 (VCAM-1), flow mediated dilatation (FMD) and carotid intima media thickness (IMT) in children with juvenile idiopathic arthritis: relation to disease activity, functional status and fatigue. Egypt Rheumatol:1-6

22. Nordal E, Zak M, Aalto K et al (2011) Ongoing disease activity and changing categories in a long-term nordic cohort study of juvenile idiopathic arthritis. Arthritis Rheum 63:2809-2818

23. Picarelli MM, Danzmann LC, Grun LK et al (2017) Arterial stiffness by oscillometric device and telomere lenght in juvenile idiopathic artrhitis with no cardiovascular risk factors: a cross-sectional study. Pediatr Rheumatol 15:34-39

24. Urban M, Pietrewicz E, Gorska A et al (2004) Lipids and homocysteine level in juvenile idiopathic arthritis. Polski merkuriusz lekarski: organ Polskiego Towarzystwa Lekarskiego 17:235-238

25. Gonçalves M, D'Almeida V, Guerra-Shinohara EM et al (2007) Homocysteine and lipid profile in children with juvenile idiopathic arthritis. Pediatr Rheumatol 5:2-9

26. Marangoni RG, Hayata AL, Borba EF et al (2011) Decreased high-density lipoprotein cholesterol levels in polyarticular juvenile idiopathic arthritis. Clinics 66:15

27. Breda L, Di Marzio D, Giannini C et al (2013) Relationship between inflammatory markers, oxidant-antioxidant status and intima-media thickness in prepubertal children with juvenile idiopathic arthritis. Clin Res Cardiol 102:63-71

28. Aulie HA (2015) Disease progression and cardiovascular risk into adulthood in juvenile idiopathic arthritis. J Rheumatol 9:42-56

29. Jednacz E, Rutkowska-Sak L (2015) Assessment of the body composition and parameters of the cardiovascular risk in juvenile idiopathic arthritis. Biomed Res Int:1-8

30. Pickard V (2017): Investigating traditional and emerging cardiovascular disease risk factors in paediatric populations with chronic inflammatory disease.; $79-81$.

31. Głowińska-Olszewska B, Bossowski A, Dobreńko E et al (2013) Subclinical cardiovascular system changes in obese patients with juvenile idiopathic arthritis. Mediat Inflamm:1-11

32. Satija M, Yadav T, Sachdev N et al (2014) Endothelial function, arterial wall mechanics and intima media thickness in juvenile idiopathic arthritis. Clin Exp Rheumatol 32:432-439

33. Evensen K, Aulie HA, Rønning OM et al (2016) Carotid atherosclerosis in adult patients with persistently active juvenile idiopathic arthritis compared with healthy controls. J Rheumatol 45:8

34. Pietrewicz E, Urban M (2007) Early atherosclerosis changes in children with juvenile idiopathic arthritis. Pol Merkur Lekarski 22:211-214

35. Dessein PH, Woodiwiss AJ, Norton GR et al (2013) Rheumatoid arthritis associated with reduced adiposity but not with unfavorable major cardiovascular risk factor profiles and enhanced carotid atherosclerosis in black Africans from a developing population: a cross-sectional study. Arthr Res Ther 15:R96-109

36. Acevedo M, Kraemer V, Tagle R et al (2011) Cardiovascular risk factors among young subjects with high carotid intima media thickness. Rev Med Chil 139:1322-1329

37. Polak JF, Pencina MJ, Meisner A et al (2010) Associations of carotid artery intima-media thickness (IMT): with risk factors and prevalent cardiovascular disease: comparison of mean common carotid artery IMT with maximum internal carotid artery IMT. J Ultrasound Med 29:1759-1768

\section{Publisher's Note}

Springer Nature remains neutral with regard to jurisdictional claims in published maps and institutional affiliations.

\section{Submit your manuscript to a SpringerOpen ${ }^{\circ}$ journal and benefit from:}

- Convenient online submission

- Rigorous peer review

- Open access: articles freely available online

High visibility within the field

- Retaining the copyright to your article

Submit your next manuscript at $\boldsymbol{\nabla}$ springeropen.com 